\title{
HER-2 neu expression in surface epithelial ovarian tumors and its relationship with clinic-pathological parameters: a pilot study
}

\author{
Abhimanyu Grover, Madhusmita Mohanty*, Kanakalata Dash
}

Department of Pathology, Kalinga Institute of Medical Sciences, Bhubaneswar, Odisha, India

Received: 05 February 2021

Revised: 23 February 2021

Accepted: 24 February 2021

\section{*Correspondence:}

Dr. Madhusmita Mohanty,

E-mail: drmadhu80@gmail.com

Copyright: (C) the author(s), publisher and licensee Medip Academy. This is an open-access article distributed under the terms of the Creative Commons Attribution Non-Commercial License, which permits unrestricted non-commercial use, distribution, and reproduction in any medium, provided the original work is properly cited.

\begin{abstract}
Background: Ovarian cancer is one of the major source of morbidity and mortality in women among all gynecological malignancies. Her2/neu expression in ovarian carcinoma has not been studied extensively in ovarian surface epithelial carcinoma. It's can be utilized towards future proposed studies as a targeted therapy in new era of treatment for ovarian malignancies.

Methods: It was a prospective study carried for 2 years. Hematoxylin and eosin stain was studied, grading, staging was evaluated for all the cases. Immunohistochemical staining with HER2/neu was done, evaluation done by 3 independent pathologists, correlation of HER2/neu with histological type, grade and stage was done.

Results: The present study included 33 cases of histologically proven epithelial ovarian neoplasm with mean age of $44.5 \pm 25.55$ years. Serous type constitutes majority of cases $(48.48 \%)$, maximum number of cases was in high grade $(57.57 \%)$ and high stage $(40.74 \%)$. Majority of tumors showed negative expression of HER2/neu i.e. $42.42 \%$. The current study found no significant correlation between HER2/neu expression and histological type, histological grade, extent of tumor (T stage) and distant metastasis. But we found a significant correlation between nodal metastasis and HER2/neu expression.
\end{abstract}

Conclusions: HER2/neu therapy can be given in borderline and low grade tumor compared to high grade tumor.

Keywords: Surface epithelial tumor, HER2/neu, Immunohistochemistry

\section{INTRODUCTION}

Ovarian cancer ranks 19th among all cancers worldwide and ranks 15 th in mortality in the year $2018 .{ }^{1}$ Incidence of ovarian cancer in India is lower than that of western countries. It affects mostly the postmenopausal women. ${ }^{2}$ Amongst all gynaecological tumour, ovarian cancer has the worst prognosis and the highest mortality rate. ${ }^{2}$ Epithelial ovarian carcinomas is by far the most common type of ovarian carcinoma. These are a group of heterogenous disease with various histological subtypes. Those histological subtypes differ in their cell of origin, pathogenesis, molecular alterations, gene expression and prognosis. $^{2}$
The HER family of receptors consists of four main members: HER-1, HER-2, HER-3, and HER-4, also known as ErbB1, ErbB2, ErbB3, and ErbB4 respectively. ${ }^{3}$ About $20-30 \%$ patients with ovarian carcinoma show an overexpression of HER2 and is an indicator of poor prognosis. ${ }^{3}$

Many studies on HER2/neu expression have been carried out for breast carcinoma. It is also expressed in other cancers such as stomach, uterine serous endometrial carcinoma, colon, bladder, uterine cervix, lungs, head and neck and oesophagus. ${ }^{4,5}$ Her $2 /$ neu expression in ovarian carcinoma has not been studied extensively. Objectives of this study was to find out the extent of HER2/neu expression in histopathological spectrum of ovarian 
epithelial carcinomas and to correlate the HER-2/Neu expression with tumour grade and stage.

\section{METHODS}

The present study was conducted in the department of Pathology, Kalinga Institute of Medical Sciences, Bhubaneswar, Odisha from September 2018 to August 2020. The study was approved by institutional ethics committee. It was a prospective study. It included 33 cases of histologically proven epithelial ovarian neoplasm. All histologically proven cases of borderline and malignant ovarian epithelial neoplasm were included in the study. Benign ovarian neoplasm, patients receiving neoadjuvant chemotherapy, poorly preserved/poorly fixed tissue were excluded from the study.

Haematoxylin and Eosin stained sections were studied and the histological features like tumor type and grade were evaluated routinely according to the criteria outlined in the World Health Organization classification of tumors.6 Immunohistochemical staining with HER2/neu anti-cerbB2 rabbit monoclonal antibody (Clone SP3) from (master diagnostica) were done on formalin fixed paraffin embedded tissue sections (4-5 micrometer thick). Positive control slides were prepared from known HER2/neu positive breast carcinoma tissue. Negative control slides were prepared from the same tissue block under study by incubating with Phosphate Buffered Saline [PBS] instead of primary antibody.

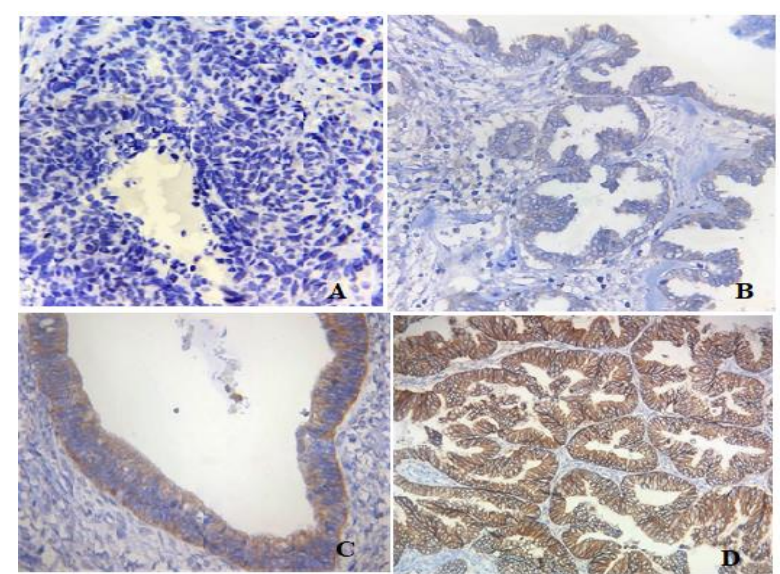

Figure 1: Expression of HER2/neu in ovarian carcinoma (A) negative expression (B) low expression

(C) moderate expression and (D) high expression.

The assessment of immunohistochemical staining was carried out by three independent pathologists. A semi quantitative system based on multiplication of intensity of reaction product and the percentage of cells showing membrane positivity in HER2/neu was done. The staining intensity was scored as follows- negative-0, low-1, moderate- 2 and high- 3 and percentage of cells was scored as: $0-5 \%$ cells- $0,6-25 \%$ cells- $1,26-50 \%$ cells- $2,51-75 \%$ cells- 3 and $>75 \%$ cells -4 (Figure 1 ). The final scores were graded as negative- 0 , low- 1 to 4 and high- 6 to $12 .{ }^{7}$ The relationship between qualitative parameters was determined using SPSS- 20. Nominal categorical data between the groups were compared using Chi-squared test. For all statistical tests, $\mathrm{p}$ value less than 0.05 was considered significant.

\section{RESULTS}

The present study included 33 number of histologically proven epithelial ovarian borderline and malignant tumors. Age range was from 19 years to 71 years with mean age of $44.5 \pm 25.55$ years (Figure 2). In our study patient presented with various clinical complaint like abdominal pain, abdominal lump, ascites, vaginal bleeding, loss of weight and loss of appetite. Among these maximum number of cases $63.63 \%$ present with abdominal lump followed by loss of weight and appetite (54.54\%), vaginal bleeding (48.48\%), ascites (42.42\%) and abdominal lump (36.36\%) (Figure 3). Detailed clinical information was collected.

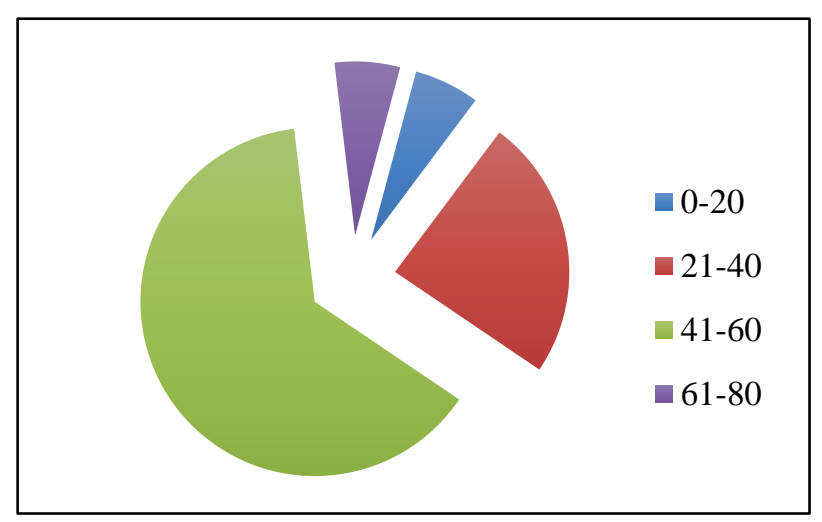

Figure 2: Age distribution of epithelial ovarian neoplasm cases $(n=33)$.

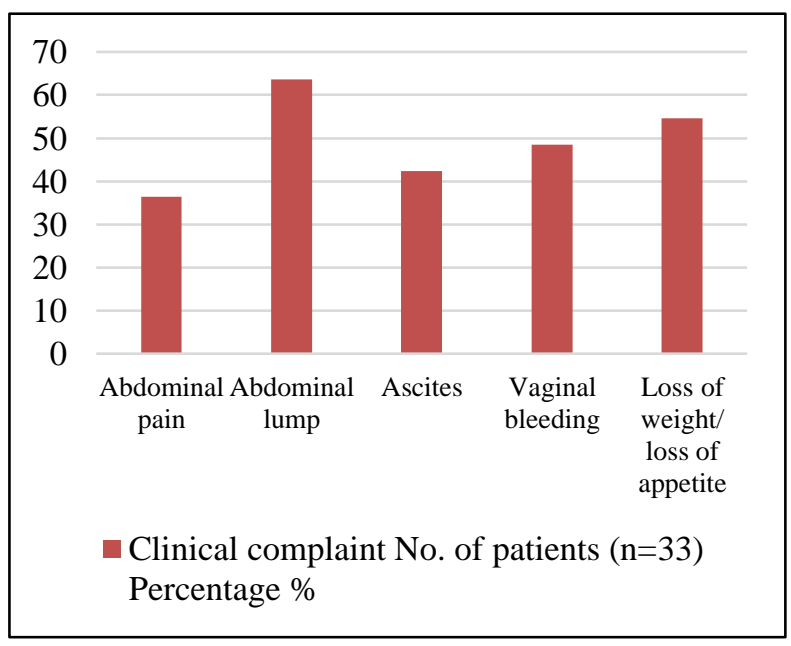

Figure 3: Distribution of cases according to their clinical complaints $(n=33)$.

The current study included four histological subtypes of epithelial ovarian neoplasms consist of serous tumors, mucinous tumors, clear cell tumors and endometrioid 
tumors. Out of 33 cases analysed serous carcinoma constituted the bulk of cases accounting for $48.48 \%$ $(16 / 33)$ followed by mucinous tumor $30.3 \%(10 / 33)$, clear cell tumor $12.12 \%(4 / 33)$ and endometrioid tumor $9.09 \%$ (3/33) (Figure 4).

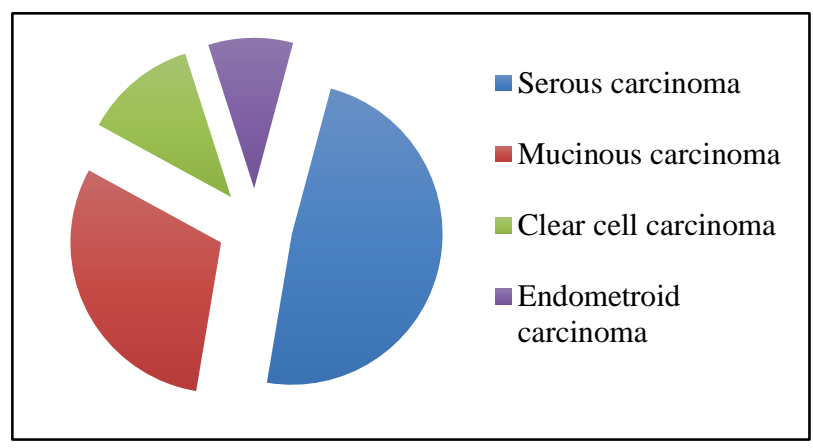

Figure 4: Distribution of histological subtypes of epithelial ovarian neoplasm $(n=33)$.

Among all ovarian carcinoma maximum number of cases were in high grade $57.57 \%$ (19/33) followed by low grade $21.21 \%(7 / 33)$ and moderate grade $9.09 \%(3 / 33)$.
Borderline ovarian tumor comprising of $12.12 \%$ (4/33) also included in our study. In the present study found maximum number of cases $40.74 \%(11 / 27)$ were found in high stage (T3) followed by $33.33 \%(9 / 27)$ in T2 and $25.93 \%(7 / 27)$ in $\mathrm{T} 1$.

Out of all 24.24\% (8/33) tumors showed high expression, $33.33 \%$ (11/33) low expression and 42.42\% (14/33) no/negative expression for HER2/NEU. Among the serous tumors $56.3 \%$ (9/16) showed negative expression followed by $31.3 \%(5 / 16)$ cases and $12.5 \%(2 / 16)$ cases showed low and high expression of HER2neu respectively. Maximum number of cases 50\% (5/10) showed high expression followed by low and negative expression of HER2 neu in mucinous carcinoma. The current study found no significant correlation between HER2 neu expression and histological type $(\mathrm{p}=0.309)$. (Table 1). The present study found that high grade and moderate grade tumors showed negative expression in maximum number of cases $8 / 19(42.1 \%)$ and $3 / 3(100 \%)$ respectively. On statistical analysis there was no significant correlation found between HER2neu expression and histological grade of tumor $(\mathrm{p}=0.566)$ (Table 1).

Table 1: Correlation of HER2/neu with histologic type and grade.

\begin{tabular}{|c|c|c|c|c|c|}
\hline \multirow{2}{*}{ Variables } & \multicolumn{4}{|c|}{ HER2/Neu } & \multirow{2}{*}{ P value } \\
\hline & Negative & Low & High & Total $(n=33)$ & \\
\hline \multicolumn{6}{|l|}{ Histologic type } \\
\hline Serous & 9 & 5 & 2 & 16 & 0.309 \\
\hline Mucinous & 2 & 3 & 5 & 10 & \\
\hline Clear cell & 1 & 2 & 1 & 4 & \\
\hline Endometrioid & 2 & 1 & 0 & 3 & \\
\hline \multicolumn{6}{|c|}{ Histologic Grade } \\
\hline Borderline & 1 & 1 & 2 & 4 & 0.566 \\
\hline Low & 2 & 3 & 2 & 7 & \\
\hline Moderate & 3 & 0 & 0 & 3 & \\
\hline High & 8 & 7 & 4 & 19 & \\
\hline
\end{tabular}

Table 2: Correlation of HER2/neu expression with TNM stage.

\begin{tabular}{|c|c|c|c|c|c|}
\hline \multirow{2}{*}{ Variables } & \multicolumn{3}{|c|}{ HER2/Neu } & \multirow{2}{*}{ Total $(\mathrm{n}=27)$} & \multirow{2}{*}{ P value } \\
\hline & Negative & Low & High & & \\
\hline \multicolumn{6}{|c|}{ Extent of tumor (T) } \\
\hline T1 & 3 & 3 & 1 & 7 & 0.343 \\
\hline $\mathbf{T 2}$ & 6 & 1 & 2 & 9 & \\
\hline T3 & 3 & 6 & 2 & 11 & \\
\hline \multicolumn{6}{|c|}{ Lymph node metastasis (N) } \\
\hline Negative & 12 & 7 & 4 & 23 & 0.047 \\
\hline Positive & 0 & 2 & 2 & 4 & \\
\hline \multicolumn{6}{|c|}{ Distant metastasis (M) } \\
\hline Negative & 12 & 9 & 4 & 25 & 0.299 \\
\hline Positive & 0 & 1 & 1 & 2 & \\
\hline
\end{tabular}

In the present study, among $\mathrm{T} 1$ cases we found same number of cases $3 / 7$ (42.9\% each) having low and negative expression of HER $2 /$ neu. T2 stage revealed maximum no. of cases showing negative expression $6 / 9$ $(66.7 \%)$. Low expression $6 / 11(54.5 \%)$ was found to be maximum number in $\mathrm{T} 3$ stage. There was no significant 
association found between the tumor stage and HER-2 expression $(\mathrm{p}$ value $=0.343)$ (Table 2$)$. The present study found significant correlation between HER2 neu expression and lymph node metastasis $(\mathrm{p}=0.047)$. Among HER2 neu expression and distant metastasis no significant correlation was found $(\mathrm{p}=0.299)$ (Table 2).

\section{DISCUSSION}

Ovarian cancer is one of the major source of morbidity and mortality in women among all gynecological malignancies all over the world.

Continuous research is going on to find out the methods for early detection, control and drug for targeted therapy to improve the survival rate. The current study found maximum number of cases $(62.5 \%)$ was in age range of 41-60 years. This was similar to study conducted by Nielsen et al with median age of 58 years, Sapna Goel et al with an age range of $<50$ years and $>50$ years. ${ }^{8,9}$

Our study comprised of maximum number of cases of serous histotype $(48.49 \%)$. This was similar to other studies conducted by Showeil et al, Asadinejad et al, Onwuka, Nielsen et al, Sapna Goel et al, and Cirstea et al. ${ }^{8-13}$ High grade tumors constituted maximum number of cases in the present study, comprising of 19 cases $(57.57 \%)$. Our findings were similar to study conducted by Nielsen et al, in which $45 \%$ tumors were poorly differentiated followed by $30 \%$ well differentiated tumors and $25 \%$ moderately differentiated tumors with a significant $\mathrm{p}$ value of $<0.001$. Similar results were found in study conducted by Goel et al in which $57.69 \%$ tumors were interpreted as high grade and $42.30 \%$ as moderate and low grade tumors, with a siginificant $\mathrm{p}$ value of $0.04 .^{9}$

Maximum number of cases did not express HER2/neu. The study conducted by Cirstea et al showed that HER2/neu was expressed in 35\% epithelial ovarian carcinoma and $54 \%$ borderline tumors. $65 \%$ ovarian carcinomas did not express HER2/neu which is similar to the observation in our study. ${ }^{13}$ Another study conducted by Goel et al revealed that $25.67 \%$ malignant ovarian tumors and $5.40 \%$ borderline tumors did not express HER2/neu. ${ }^{13}$ Study by Nielsen et al showed similar results with $65 \%$ ovarian carcinomas not expressing HER2/neu. ${ }^{8}$ Elham Asadinejad et al in his study demonstrated that $69 \%$ malignant ovarian tumors did not express HER2/neu. ${ }^{11}$ Similar results were observed in study conducted by Onwuka et al where $74 \%$ malignant epithelial ovarian tumor did not express HER2/neu. ${ }^{12}$

The current study found no significant correlation between HER2 neu expression and histological type $(\mathrm{p}=0.309)$. Interestingly, mucinous tumors were observed to show strong HER2/neu expression. In comparison to mucinous tumor, serous tumor showed more number of negative expression of HER2/neu. Similar results were observed in study conducted by Onwuka et al with $100 \%$ endometrioid tumors showing no expression of
HER2/neu, and $87.1 \%$ serous tumors and $64.3 \%$ mucinous tumors showing negative HER2/neu expression. ${ }^{12}$ However similar to our study $35.7 \%$ mucinous tumors expressed high expression of HER2/neu followed by $12.9 \%$ serous tumors with ( $p$ value $=0.080$ ). No significance association was found between HER2/neu expression and histologic subtyping. In contrast to our study, Nielsen et al found a significant association between histologic subtype and HER2/neu expression $(\mathrm{p}$ value $=0.021){ }^{8}$

The present study found that as the grade of the tumor increases from borderline to high grade, expression of HER2/neu got reversed from high expression to negative expression. Similar results were observed in study conducted by Onwuka et al. ${ }^{12}$ No significant association between HER-2 and tumor grade was observed ( $p$ value $=0.141$ ). Other studies conducted by Asadinejad et al showed similar results ( $\mathrm{p}$ value $=0.567) .{ }^{11}$ Contradicting results were found in studies conducted by Cirstea et al, Showeil et al, Goel et al and Nielsen et al. ${ }^{8-10,13}$ These studies demonstrated that there was significant association between different grades of ovarian epithelial tumors and HER-2 expression. This difference was due to larger study sample taken into account by them and differences in race, age and population of study.

Study by Asadinejad et al showed similar results as seen in our study, with no significant association between HER-2 and tumor stage $(\mathrm{p}$ value $=0.929) .{ }^{11}$ Goel et al demonstated no statistical association between the two parameters $(\mathrm{p}$ value $=0.23) .{ }^{9}$ Similar study by Cirstea et al and Nielsen et al contradicted our results, by demonstrating a significance association between stage 2 and stage 3 than stage 1 tumor ( $p$ value $=0.001){ }^{8,13}$ The present study found significant correlation between HER2 neu expression and lymph node metastasis $(\mathrm{p}=0.047)$. All the lymph node metastasis and distant metastasis cases showed low and high expression of HER2 neu, no negative expression found. Among HER2 neu expression and distant metastasis no significant correlation was found $(\mathrm{p}=0.299)$. except the present study no other study has compared lymph node metastasis and distant metastasis with HER2/neu expression.

\section{Limitations}

Limitation of this study was lesser number of sample size and unavailability of all the histological sub types of surface epithelial ovarian cancer.

\section{CONCLUSION}

The present study found strong expression of HER2/neu in high grade mucinous tumors. As the grade of the tumor increases from borderline to high grade, expression of HER2/neu got reversed from high expression to negative expression. We observed a significant association between the nodal metastasis and upregulation of HER2/neu expression. So, HER2/neu therapy can be 
given in borderline and low grade tumor in comparison to high grade tumor. Further study can be conducted with large sample size.

Funding: No funding sources

Conflict of interest: None declared

Ethical approval: The study was approved by the Institutional Ethics Committee

\section{REFERENCES}

1. Torre LA, Trabert B, DeSantis CE, Miller KD, Samimi G, Runowicz CD, et al. Ovarian cancer statistics, 2018. Cancer J Clin. 2018;68:284-96.

2. Reid BM, Permuth JB, Sellers TA. Epidemiology of ovarian cancer: a review. Cancer Biol Med. 2017;14:9-32.

3. Iqbal N, Iqbal N. Human Epidermal Growth Factor Receptor 2 (HER2) in Cancers: Overexpression and Therapeutic Implications. Mol Biol Int. 2014;2014:852748.

4. Fukushige SI, Matsubara K, Yoshida MI, Sasaki MO, Suzuki TO, Semba K, et al. Localization of a novel v-erbB-related gene, c-erbB-2, on human chromosome 17 and its amplification in a gastric cancer cell line. Molecul Cellul Biol. 1986;6(3):9558.

5. Reichelt U, Duesedau P, Tsourlakis MC, Quaas A, Link BC, Schurr PG, et al. Frequent homogeneous HER-2 amplification in primary and metastatic adenocarcinoma of the esophagus. Modern Pathol. 2007;20(1):120-9.

6. Prat J. Ovary, Fallopian Tube, and Primary Peritoneal Carcinoma. AJCC Cancer Staging Manual, Eight Edition. 2015;55:689-98.

7. Cirstea AE, Stepan AE, Margaritescu C, Zavoi RE, Olimid DA, Simionescu CE. The immunoexpression of EGFR, HER2 and HER3 in malignant serous ovarian tumors. Rom J Morphol Embryol. 2017;58(4):1269-73.

8. Nielsen JS, Jakobsen E, Hølund B, Bertelsen K, Jakobsen A. Prognostic significance of p53, Her-2, and EGFR overexpression in borderline and epithelial ovarian cancer. Int $\mathbf{J}$ Gynecol Canc. 2004;14(6).

9. Goel S, Mehra M, Yadav A, Sharma M.A Comparative study of HER-2/neu Oncogene in benign and malignant ovarian tumors. Int $\mathbf{J}$ Scient Stud. 2014;2:21-7 .

10. Showeil R, Romano C, Valganon M, Lambros M, Trivedi P, Van Noorden S, et al. The status of epidermal growth factor receptor in borderline ovarian tumours. Oncotarget. 2016;7(9):10568.

11. Asadinejad E, Abdirad A, Nili F, Soleimani V. HER2 Overexpression in Borderline and Malignant Ovarian Tumors: A Cross-sectional Study in an Iranian Population and Literature Review. Mid East J Canc. 2018;9(4):300-9.

12. Ndukwe CO, Asomugha LA, Ukah CO. Profile of human epidermal growth factor receptor 2 expression in epithelial ovarian carcinomas: A multicenter study from southeast Nigera. J Scientif Soc. 2018 ;5:57-62.

13. Cirstea AE, Stepan AE, Margaritescu C, Zavoi RE, Olimid DA, Simionescu CE. The immunoexpression of EGFR, HER2 and HER3 in malignant serous ovarian tumors. Rom J Morphol Embryol. 2017;58(4):1269-73.

Cite this article as: Grover A, Mohanty M, Dash K. HER-2 neu expression in surface epithelial ovarian tumors and its relationship with clinic-pathological parameters: a pilot study. Int J Reprod Contracept Obstet Gynecol 2021;10:1363-7. 